\title{
Review Paper on Efficient VLSI Architecture for Carry Select Adder
}

\author{
Anamika Mandal \\ M. Tech. Scholar \\ NRI Institute of Information \\ Science \& Technology \\ Bhopal (M.P.)-462021, India
}

\author{
Puran Gour \\ Associate Professor \\ NRI Institute of Information \\ Science \& Technology \\ Bhopal (M.P.)-462021, India
}

\author{
Braj Bihari Soni \\ Assistant Professor \\ NRI Institute of Information \\ Science \& Technology \\ Bhopal (M.P.)-462021, India
}

\begin{abstract}
A adder is one of the key hardware blocks in most digital and high performance systems such as FIR filters, digital signal processors and microprocessors etc. With advances in technology, many researchers have tried and are trying to design many types of adder such as ripple carry adder, carry skip adder, carry a look head adder and carry select adder. Among this adder carry select adder is the high speed, low power consumption and hence less area or even combination of them in adder. However area and speed are two conflicting constraints.
\end{abstract}

\section{Keywords}

Ripple Carry Adder, Carry Select Adder (CSLA), Booth Encoder (BEC)

\section{INTRODUCTION}

Expansion typically affects broadly the general execution of advanced frameworks and a significant number juggling capacity. In electronic applications adders are most generally utilized. Applications where these are utilized are multipliers, DSP to execute different calculations like FFT, FIR and IIR. Wherever idea of increase comes adders come into the photo. As we probably am aware a great many guidelines for each second are performed in microchips. In this way, speed of operation is the most essential requirement to be considered while planning multipliers.

Enhanced adders create conveys at the same time [1]. These adders utilize the rule that the convey from every piece position may be produced autonomously as an unequivocal capacity of all the less noteworthy numbers to be added and augend bits. Be that as it may, as a result of the inalienable confinements in accessible segments, the constructors of concurrent convey era adders are not generally functional.

Duplication is a principal operation in most flag handling calculations. Multipliers have expansive zone, long inertness and expend impressive force. Along these lines low-control multiplier outline has been a critical part in low-control VLSI framework plan. There has been broad work on low-control multipliers at innovation, physical, circuit and rationale levels. A framework's execution is by and large controlled by the execution of the multiplier in light of the fact that the multiplier is for the most part the slowest component in the framework. Besides, it is by and large the most range devouring. Consequently, upgrading the pace and zone of the multiplier is a noteworthy configuration issue. On the other hand, region and rate are normally clashing limitations so that enhancing rate comes about generally in bigger regions. Therefore, an entire range of multipliers with distinctive zone speed limitations has been outlined with completely parallel. The rest of the paper is organized as follows. In section 2, a brief about ripple carry adder, carry select adder and carry skip is given. In section 3 carry look head adder is introduced along with partitioning methodology. Also a new architecture with clock sharing is introduced. Section 4 provides the simulation results obtained. Section 5 provides the conclusion and future scope obtained.

\section{ADDITION ALGORITHM}

- Ripple Carry Adder

This procedure is an asynchronous addition used in the first electronic computers. Addition of binary numbers of several digits is accomplished in the same manner as that of decimal numbers.

Concatenating the $\mathrm{N}$ full adders forms $\mathrm{N}$ bit Ripple carry adder. In this carry out of previous full adder becomes the input carry for the next full adder. It calculates sum and carry according to the following equations. As carry ripples from one full adder to the other, it traverses longest critical path and exhibits worst case delay.

$$
\begin{aligned}
& S_{i}=A_{i} \oplus B_{i} \oplus C_{i} \\
& C_{i+1}=A_{i} \bullet B_{i}+B_{i} \bullet C_{i}+C_{i} \bullet A_{i}
\end{aligned}
$$

Where $\mathrm{i}=0,1,2,3 \ldots \mathrm{n}-1$

RCA is the slowest in all adders but it is very compact in size. If the ripple carry adder is implemented by concatenating $\mathrm{N}$ full adders, the delay of such an adder is $2 \mathrm{~N}$ gate delays from $\mathrm{C}_{\mathrm{in}}$ to $\mathrm{C}_{\text {out }}$. The delay of adder increases linearly with increase in number of bits. Block diagram of RCA is shown in Figure 1.

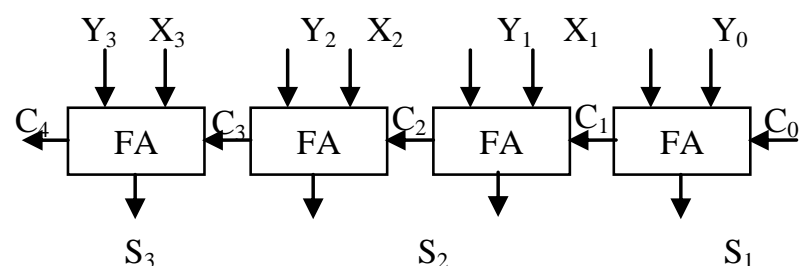

Figure 1: Block Diagram of RCA

- Carry Select Adder

In Carry select adder scheme, blocks of bits are added in two ways: one assuming a carry-in of 0 and the other with a carryin of 1.This results in two precomputed sum and carry-out signal pairs $\left(\boldsymbol{S}_{i-1: k}^{0}, \boldsymbol{C}_{i}^{0}, ; \boldsymbol{S}_{i-1: k}^{1}, \boldsymbol{C}_{i}^{1}\right)$, later as the block's true carry-in $\left(\boldsymbol{C}_{k}\right)$ becomes known, the correct signal pairs are selected. Generally multiplexers are used to propagate carries. 


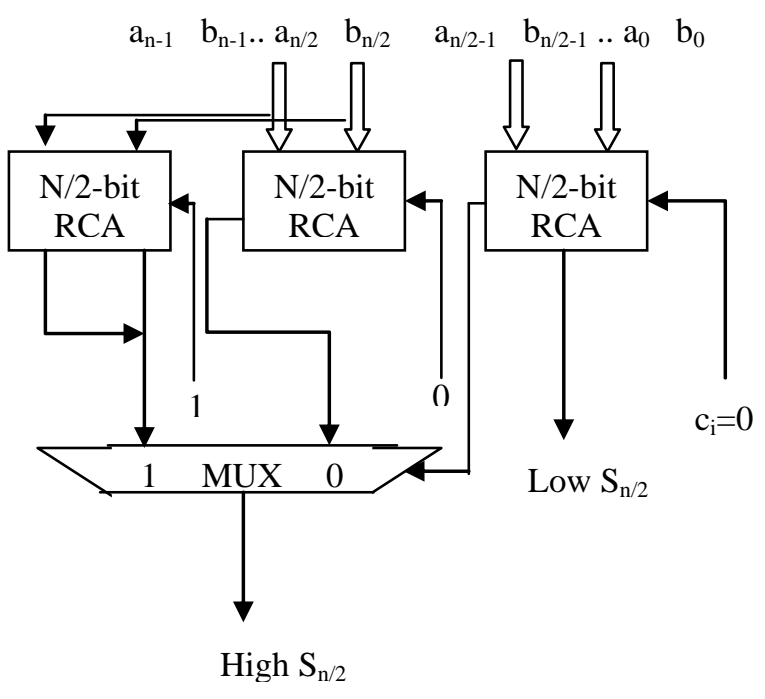

Figure 2: A Carry Select Adder with 1 level using n/2- bit RCA

Because of multiplexers larger area is required. Have a lesser delay than Ripple Carry Adders (half delay of RCA). Hence we always go for Carry Select Adder while working with smaller no of bits.

The CSLA is used in many computational systems to alleviate the problem of carry propagation delay by independently generating multiple carries and then select a carry to generate the sum [1]. However, the CSLA is not area efficient because it uses multiple pairs of Ripple Carry Adders (RCA) to generate partial sum and carry by considering carry input $C_{i}=0$ and $C_{i}=1$, then the final sum and carry are selected by the multiplexers (mux).

\section{LITERATURE REVIEW}

Samiappa Sakthikumaran et al. [2011], Carry Select Adder (CSA) is known not the quickest viper among the customary snake structures. It is utilized as a part of numerous information preparing units for acknowledging speedier number juggling operations. We introduce an inventive CSA structural engineering. It utilizes a novel incrementer circuit in the meantime phases of the CSA. Acceptance of the proposed configuration is done through outline and execution of 16, 32 and 64-bit viper circuits. The proposed structure ends up being less demanding answer for enhancing the pace of convey select viper. The ordinary CSA experiences the hindrance of involving more chip range, which has been overcome utilizing the proposed 4-bit incrementer unit. The proposed unit is additionally found to devour less power. The proposed convey select snake can be utilized to accelerate the last expansion in parallel multiplier circuits and different architectures which utilizes viper circuits. The structure has been incorporated with Synopsys back-end pack utilizing xilinx instrument with vertex gadget crew.

Sajesh Kumar et al. [2012], Elite computerized viper with decreased zone and low power utilization is an imperative configuration limitation for cutting edge processors. The rate of operation of such a snake is restricted via convey engendering from data to yield. Our work depends on planning a streamlined viper for cutting edge processors. This paper talks about the usage of Carry Select Adder without utilizing MUX for definite choice. Our methodology utilizes to begin with, the execution of $\operatorname{cin}=0$ snake and after that Excess 1 viper. Abundance 1 snake is outlined in a manner that it turns into an initial zero discovering rationale and replaces the last MUX stage utilized as a part of customary methodology. Parallel viper arrangement is additionally used to decrease the deferral between stages. Uprooting the MUX stage will lessen the zone and additionally proliferation deferral to give much higher execution for the snake. The Kogge Stone parallel methodology will offer alternative to produce quick convey for middle of the road stages. The viper is executed on Spartan 3E FPGA and is contrasted and CSA with MUX, Kogge Stone snake and FPGA viper. Results demonstrate that the new viper gives lessened range and better speed contrasted with different adders.

B. Ramkumar et al. [2012], Convey Select Adder (CSLA) is one of the quickest adders utilized as a part of numerous information preparing processors to perform quick numbercrunching capacities. From the structure of the CSLA, it is clear that there is extension for diminishing the zone and power utilization in the CSLA. This work utilizes a straightforward and proficient entryway level alteration to altogether lessen the region and force of the CSLA. In view of this change 8-, 16-, 32-, and 64-b square-root CSLA (SQRT CSLA) structural planning have been created and contrasted and the consistent SQRT CSLA building design. The proposed configuration has diminished range and power as contrasted and the standard SQRT CSLA with just a slight increment in the deferral. This work assesses the execution of the proposed plans as far as postponement, range, power, and their items by hand with consistent exertion and through specially craft and design in $0.18-\mathrm{m}$ CMOS process innovation. The outcomes investigation demonstrates that the proposed CSLA structure is superior to the standard SQRT CSLA. 


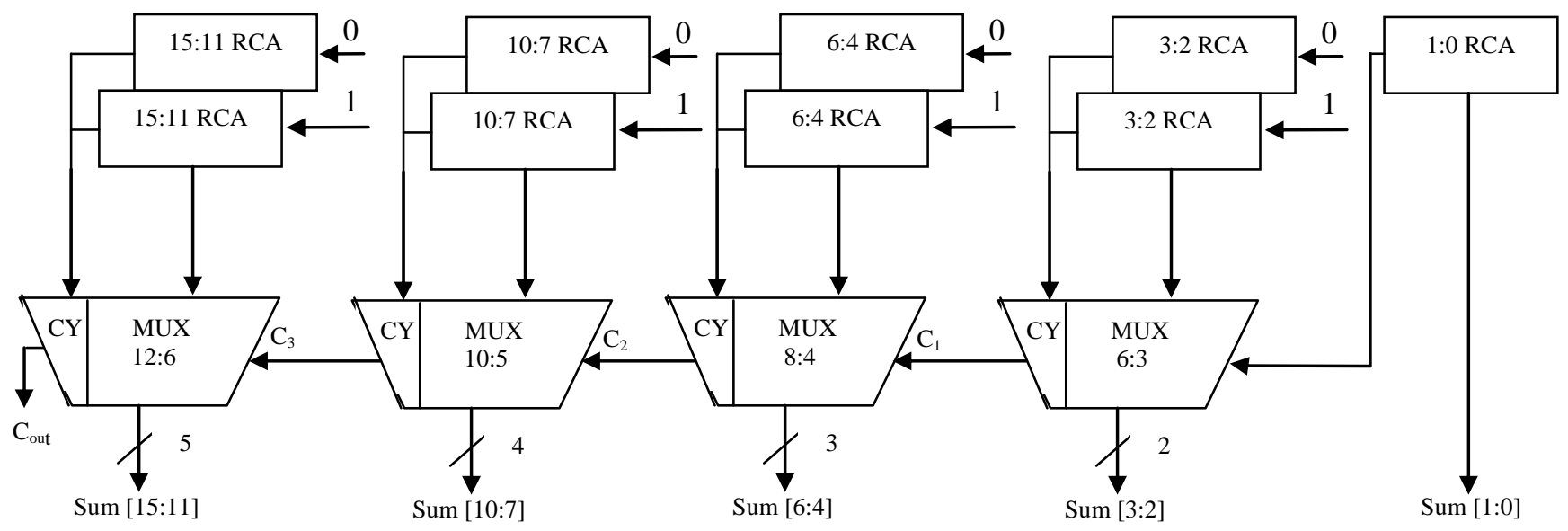

Figure 3: Design Structure of 16-bit Carry Select Adder

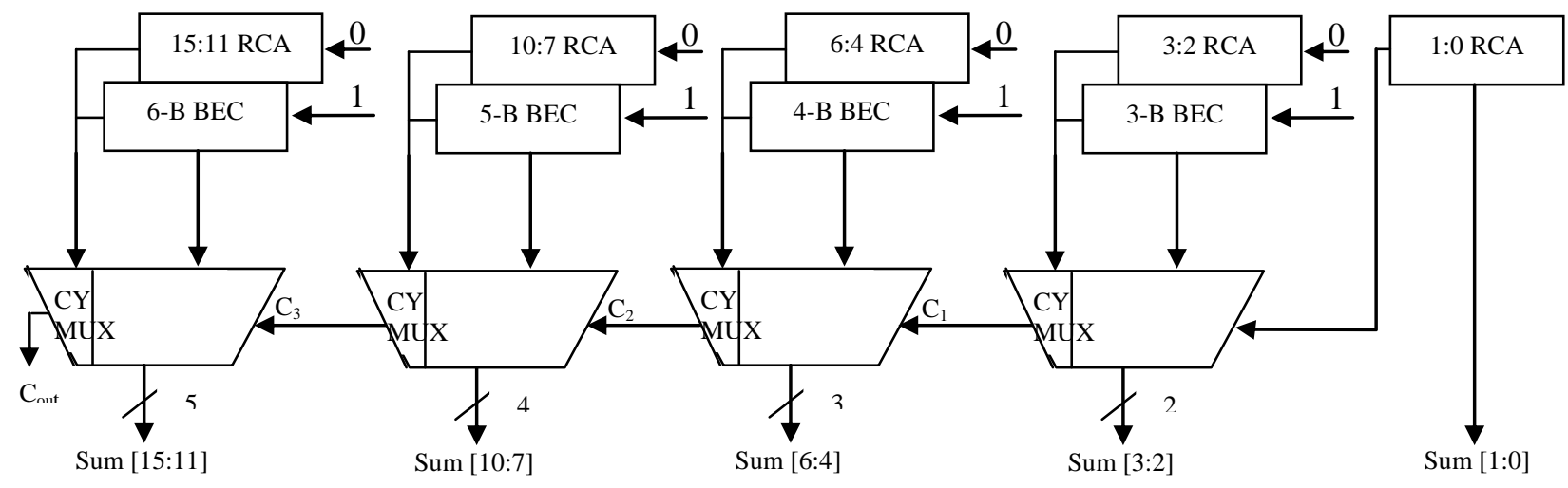

Figure 4: Design Structure of 16-bit Modified Carry Select Adder. The parallel RCA $C_{i}=1$ is replaced with BEC

Hasan Krad et. al. [2008] We have designed a specific parallel architecture for the computation of the radix $\mathrm{r}$ Fast Fourier Transform, which reduces almost 50\% the area of other designs with a similar performance. This reduction is mainly due to three factors.

Table 1: Compared Result for 16-B SQRT CSA using RCA and 16-B SQRT CSA using BEC in different Device Family

\begin{tabular}{|c|c|c|c|c|}
\hline Design & $\begin{array}{l}\text { Device } \\
\text { Family }\end{array}$ & $\begin{array}{l}\text { Number } \\
\text { of Slice }\end{array}$ & $\begin{array}{l}4 \text { Input } \\
\text { LUTs }\end{array}$ & MCPD \\
\hline $\begin{array}{c}\text { 16-B SQRT } \\
\text { CSA using } \\
\text { RCA }\end{array}$ & & $\begin{array}{c}27 \text { out of } \\
768\end{array}$ & $\begin{array}{c}46 \text { out of } \\
1536\end{array}$ & $\begin{array}{c}20.320 \\
n s\end{array}$ \\
\hline $\begin{array}{c}\text { 16-B SQRT } \\
\text { CSA using } \\
\text { BEC }\end{array}$ & $\begin{array}{c}\text { Spartan- } \\
3\end{array}$ & $\begin{array}{c}23 \text { out of } \\
768\end{array}$ & $\begin{array}{c}43 \text { out of } \\
1536\end{array}$ & $\begin{array}{c}18.998 \\
\text { ns }\end{array}$ \\
\hline $\begin{array}{c}\text { 16-B SQRT } \\
\text { CSA using } \\
\text { RCA }\end{array}$ & \multirow[b]{2}{*}{$\begin{array}{c}\text { Spartan- } \\
3 \mathrm{E}\end{array}$} & $\begin{array}{c}27 \text { out of } \\
960\end{array}$ & $\begin{array}{c}46 \text { out of } \\
1920\end{array}$ & $\begin{array}{c}15.933 \\
n s\end{array}$ \\
\hline $\begin{array}{c}\text { 16-B SQRT } \\
\text { CSA using } \\
\text { BEC }\end{array}$ & & $\begin{array}{c}23 \text { out of } \\
960\end{array}$ & $\begin{array}{c}43 \text { out of } \\
1920\end{array}$ & $\begin{array}{c}14.744 \\
\text { ns }\end{array}$ \\
\hline
\end{tabular}

\section{COMPARISION OF CSA RESULT}

All the designing and experiment regarding algorithm that we have mentioned in this paper is being developed on Xilinx $6.2 \mathrm{i}$ Sparten 2, Vertex 2 and Vertex E updated version. Xilinx $6.2 \mathrm{i}$ has couple of the striking features such as low memory requirement, fast debugging, and low cost. The latest release of $\mathrm{ISE}^{\mathrm{TM}}$ (Integrated Software Environment) design tool provides the low memory requirement approximate 27 percentage low. ISE $6.2 \mathrm{i}$ that provides advanced tools like smart compile technology with better usage of their computing hardware provides faster timing closure and higher quality of results for a better time to designing solution.

Table 2: Compared Result for 16-B SQRT CSA using RCA and 16-B SQRT CSA using BEC in Vertex 2 Device Family using

\begin{tabular}{|c|c|c|c|c|}
\hline Design & $\begin{array}{l}\text { Device } \\
\text { Family }\end{array}$ & $\begin{array}{l}\text { Number } \\
\text { of Slice }\end{array}$ & $\begin{array}{l}4 \\
\text { Input } \\
\text { LUTs }\end{array}$ & MCPD \\
\hline $\begin{array}{c}\text { 64-B } \\
\text { SQRT } \\
\text { CSA } \\
\text { using } \\
\text { RCA }\end{array}$ & \multirow{2}{*}{$\begin{array}{c}\text { Spartan- } \\
3\end{array}$} & $\begin{array}{l}106 \text { out } \\
\text { of } 768\end{array}$ & $\begin{array}{c}188 \\
\text { out } \\
\text { of } \\
1536\end{array}$ & $\begin{array}{c}58.602 \\
\text { ns }\end{array}$ \\
\hline $\begin{array}{c}\text { 64-B } \\
\text { SQRT } \\
\text { CSA } \\
\text { using } \\
\text { BEC }\end{array}$ & & $\begin{array}{l}94 \text { out } \\
\text { of } 768\end{array}$ & $\begin{array}{c}172 \\
\text { out } \\
\text { of } \\
1536\end{array}$ & $\begin{array}{c}57.588 \\
n s\end{array}$ \\
\hline
\end{tabular}




\begin{tabular}{|c|c|c|c|c|}
\hline $\begin{array}{c}64-B \\
\text { SQRT } \\
\text { CSA } \\
\text { using } \\
\text { RCA }\end{array}$ & \multirow{2}{*}{$\begin{array}{c}\text { Spartan- } \\
3 \mathrm{E}\end{array}$} & $\begin{array}{c}106 \text { out } \\
\text { of } 960\end{array}$ & $\begin{array}{c}188 \\
\text { out } \\
\text { of } \\
1920\end{array}$ & $\begin{array}{c}48.102 \\
n s\end{array}$ \\
\hline $\begin{array}{c}64-B \\
\text { SQRT } \\
\text { CSA } \\
\text { using } \\
\text { BEC }\end{array}$ & & $\begin{array}{l}94 \text { out } \\
\text { of } 960\end{array}$ & $\begin{array}{c}172 \\
\text { out } \\
\text { of } \\
1920\end{array}$ & $45.738 \mathrm{~ns}$ \\
\hline
\end{tabular}

\section{CONCLUSION}

We learned about distinctive adders among analyzed them by diverse criteria like number of cut and Time with the goal that we can judge to know which viper was most appropriate for circumstance. Subsequent to contrasting all we accompanied a conclusion that Carry Look-head Adders are most appropriate for circumstances where Speed is the main criteria. Also Ripple Carry Adders are most appropriate for Low Power Applications. Yet, Among all the Carry Look Ahead Adder had the minimum Area-Delay item that lets us know that, it is suitable for circumstances where both low power and speed are a criteria such that we require an appropriate harmony between both similar to the case with our Paper.

\section{REFERENCES}

[1] B. Ramkumar and Harish M Kittur, "Low-Power and AreaEfficient Carry Select Adder", IEEE Transsactions on Very Large Scale Integration (VLSI) Systems, VOL. 20, No. 2 Feb 2012

[2] Sajesh Kumar U.a, Mohamed Salih K. K.b Sajith K., "Design and Implementation of Carry Select Adder without Using Multiplexers", 2012 1st International Conference on Emerging Technology Trends in Electronics, Communication and Networking 978-1-4673-16279/12/\$31.00 @2012 IEEE.

[3] Samiappa Sakthikumaran1, S. Salivahanan, V. S. Kanchana Bhaaskaran2, V. Kavinilavu, B. Brindha and C. Vinoth, "A Very Fast and Low Power
Carry Select Adder Circuit”, 978-1-4244 -8679-3 /11/\$26.00 @2011 IEEE.

[4] Padma Devi, Ashima Girdher, Balwinder Singh, "Improved Carry Select Adder with Reduced Area and Low Power Consumption", International Journal of Computer Applications (0975 - 8887) Volume 3 - No.4, June 2010.

[5] Z. Abid, H. El-Razouk and D.A. El-Dib, "Low power multipliers based on new hybrid full adders", Microelectronics Journal, Volume 39, Issue 12, Pages 1509-1515, 2008.

[6] Hasan Krad and Aws Yousif Al-Taie, "Performance Analysis of a 32-Bit Multiplier with a Carry-Look-Ahead Adder and a 32-bit Multiplier with a Ripple Adder using VHDL", Journal of Computer Science 4 (4): 305-308, 2008.

[7] Wang, Y. Pai, C.Song, X., "The design of hybrid carry look ahead/ carry-select adders", Circuits and Systems II: Analog and Digital Signal Processing, IEEE Transactions on Volume 49, pp.16-24, 2002.

[8] YotmgjoonKim and Lee-Sup Kim, "A Low Power Carry Select Adder with Reduced Area", 0-7803-66859/01/\$10.0002001 TEEE.

[9] W. Jeong and K. Roy, "Robust high-performance low power adder", Proc. of the Asia and South Pacific Design Automation Conference, pp. 503-506, 2003.

[10] Y. Kim and L-S Kim, "64-bit carry-select adder with reduced area", Electronics Letters, vol. 37, pp. 614-615, May 2001.

[11] O. Kwon, E. Swartzlander, and K. Nowka, "A fast hybrid carry-look ahead/carry-select adder design", Proc. of the $11^{\text {th }}$ Great Lakes symposium on VLSI, pp.149-152, March 2001.

[12] Adilakshmi Silveru, M. Bharathi, "Design of Kogge-Stone and Brent Kung Adders using Degenerate Pass Transistor Logic", International Journal of Emerging Science and Engineering Vol.- I, Issue- 4 , Febrnary 2013. 